\title{
Variação sazonal do perfil batimétrico do Açude do Saco, município de Serra Talhada, Pernambuco, Brasil
}

Josimar Robson da Cruz Lima ${ }^{1}$

Renata Akemi Shinozaki Mendes ${ }^{2}$

\section{Resumo}

Os perfis batimétricos são atualmente ferramentas importantes para conhecer melhor as características morfométricas de corpos-d'água e suas possíveis alterações. Foram realizados amostragens e levantamentos batimétricos trimestralmente (setembro e dezembro de 2010, março e junho de 2011). Os dados coletados nas batimetrias foram interpolados utilizando o software Surfer 8.0 para confecção dos MDT (modelos digitais do terreno) e cálculos de volume reais e estimados. Evidenciou-se com base nos perfis batimétricos que o açude possui ao longo de seu curso ampla variação de profundidade. O volume aproximado variou bastante, indo de $19.738 .857 \mathrm{~m}^{3}$ no terceiro levantamento até $35.319 .065 \mathrm{~m}^{3}$ no quarto, quando atingiu o maior volume observado. Nesse período não ocorreu assoreamento significativo no açude. Toda a variação encontrada no açude mostra que a principal fonte de abastecimento de água são as chuvas. Apesar do variado volume encontrado, o açude apresentou condições para o desenvolvimento de atividades como pesca e aquicultura.

Palavras-chave: Perfis batimétricos. Açude. MDT.

\section{Introdução}

O Brasil abrange uma área com mais de 8,5 milhões de quilômetros quadrados, possuindo uma grande disponibilidade de recursos naturais, como pode ser constatado pelos complexos hídricos, distribuídos por quase todo o território (BICUDO; TUNDISI; SCHEUENSTUHL, 2010).

Em locais onde não havia essa riqueza em recursos hídricos e ainda afetado pela má distribuição das chuvas, buscaram-se alternativas para suprir as necessidades da população. Uma das alternativas viáveis e bem-sucedidas foi a implantação de lagos artificiais, que têm como objetivo acumular água oriunda das chuvas.

Segundo Esteves (1998), no Brasil, as represas e açudes são formados principalmente pelo represamento de rios para atender objetivos de abastecimento de água, regularização de cursos, geração de energia elétrica, irrigação, navegação, recreação, entre outros. Em adição, este autor cita que os lagos artificiais brasileiros recebem várias denominações como açudes, represas e reservatórios, as quais são sinônimas, uma vez que esses ecossistemas têm a mesma origem e finalidade.

O nordeste brasileiro é classificado como a área que tem a maior densidade de açudes construídos no país de acordo com Guimarães et al. (2008). A prática da construção de açudes de pequeno ou médio porte originou-se da necessidade precípua da população de armazenar água para os períodos de estiagem.

1 Universidade Federal Rural de Pernambuco, aluno pesquisador. josimar.robson@gmail.com. Rua Dom Manoel de Medeiros, s/n, Dois Irmãos, Recife (PE), CEP: 52171-900.

2 Universidade Federal Rural de Pernambuco, professora pesquisadora. renataasm@gmail.com. 
Com o intuito de amenizar os problemas gerados pelas secas, várias políticas públicas foram criadas pelo Governo Federal nas décadas de 1940, 1950 e 1960 e, entre elas, houve o incentivo à construção de grandes reservatórios para armazenamento da água de chuva. Para tanto, o Departamento Nacional de Obras Contra a Seca (DNOCS), outrora Inspetoria de Obras Contra a Seca (IOCS), depois Inspetoria Federal de Obras Contra a Seca (IFOCS), foi o primeiro órgão federal a tratar os problemas causados pela seca por meio da construção de açudes (SOUZA JUNIOR, 2009).

O DNOCS, na década de 30, construiu na cidade de Serra Talhada, interior do estado de Pernambuco, o Açude do Saco, localizado na Fazenda Saco (ANDRADE et al. 2009), ocupando uma área total de 600 hectares, com um volume de cerca de 36 milhões de metros cúbicos (ALMEIDA; LIMA, 2009). Desempenha, até os dias atuais, um papel de grande importância para a população da cidade e para as comunidades que vivem em seu entorno.

A batimetria pode ser definida como sendo o conjunto dos princípios, métodos e convenções utilizados para determinar a medida do contorno, dimensão e da posição relativa da superfície submersa dos mares, rios, lagos, açudes, represas e canais (GUIMARÃES et al., 2008).

Uma ferramenta de grande importância para o conhecimento das características morfométricas de corpos-d'água é a elaboração de cartas batimétricas, as quais possibilitam um maior entendimento da estrutura e do funcionamento dos ambientes aquáticos. Esses mapas constituem um importante subsídio para a realização de estudos sobre a evolução de assoreamento, qualidade da água e ictiofauna, entre outros. 0 conjunto dessas informações torna-se de grande valia no direcionamento de ações de conservação de corpos-d'água (RESCK et al., 2007).

Nos reservatórios do semiárido nordestino brasileiro, submetidos à elevada evaporação e irregularidade da precipitação pluviométrica, os estudos em curto período de tempo, aliados aos estudos morfométricos e climáticos, tornam-se fundamentais como base teórica e para o entendimento dos padrões de comportamento da qualidade da água e dos processos que os produzem, sendo importante para estudos de desenvolvimento de programas, desenvolvimento de programas de manejo de corpos aquáticos, viabilizando a tomada de decisões para mitigar os impactos ambientais negativos decorrentes das atividades antrópicas desenvolvidas nos reservatórios e nas suas bacias de drenagem (DINIZ; BARBOSA; OVRUSKI, 2006).

Tendo sido construído há mais de 70 anos, esta é a primeira vez que o Açude do Saco é submetido a um levantamento batimétrico, o que torna este um estudo de grande importância, levando-se em conta os benefícios advindos deste trabalho e a importância do lago para a população.

Diversos trabalhos acerca dos corpos-d'água artificiais foram desenvolvidos no Brasil, sendo avaliada a caracterização da água de açudes com peixes no semiárido pernambucano (LIMA; CAMPECHE; PEREIRA, 2009); os parâmetros morfométricos da Lagoa da Pampulha, Belo Horizonte, Brasil (RESCK et al., 2007); a batimetria do Açude Paraíso São Francisco (PB) (GUIMARÃES; RIBEIRO; VIEIRA, 2009); o assoreamento do Lago Bonsucesso, Jataí (GO) (SILVA, 2007); a caracterização limnológica e morfométrica de açudes dependentes de chuva povoados com tambaqui (Colossoma macropomum) no semiárido nordestino (CAMPECHE et al., 2009); a hidroquímica dos Lagos Bolonha e Água Preta, mananciais de Belém (PA) (SODRÉ, 2007); o uso de geotecnologia para análise da bacia hidrográfica do açude Cachoeira dos Alves, município de Itaporanga, Paraíba (PB) (GUIMARÃES et al., 2008); a caracterização morfométrica e suas implicações na limnologia de lagoas do Pantanal Norte (FANTIN-CRUZ; LOVERDE-OLIVEIRA; GIRARD, 2008).

Essa relevância em relação aos estudos batimétricos tem sido observada não só no Brasil, mas também em diversos trabalhos desenvolvidos em todo o mundo, como exemplo, podem ser citados 
o estudo limnológico do Lago de Guija, determinando o estado de eutrofização (PAREDES, 2008) e o mapeamento da geomorfologia e perfil batimétrico do Lago de Catemaco, em Veracruz, México (PÉREZ-ROJAS; BERNEO, 1992).

Com base no exposto, o presente trabalho teve como objetivo verificar as variações sazonais dos perfis batimétricos do Açude do Saco, Serra Talhada (PE).

\section{Material e métodos}

\section{Área de estudo}

O estudo foi desenvolvido no Açude do Saco, situado na Fazenda Saco, cidade de Serra Talhada. A referida fazenda possui uma área estimada de 3.200 hectares, tendo em seu interior o Instituto Agronômico de Pernambuco (IPA) (Figura 1). 0 açude possui uma área estimada de 500 hectares e volume médio de água por volta de $36.000 .000 \mathrm{~m}^{3}$. Esse, por sua vez, desempenha papel de grande importância social e econômica para a população do seu entorno, principalmente por seu potencial pesqueiro.

Figura 1. Localização da área de coleta de dados no Açude do Saco, cidade de Serra Talhada, no estado de Pernambuco

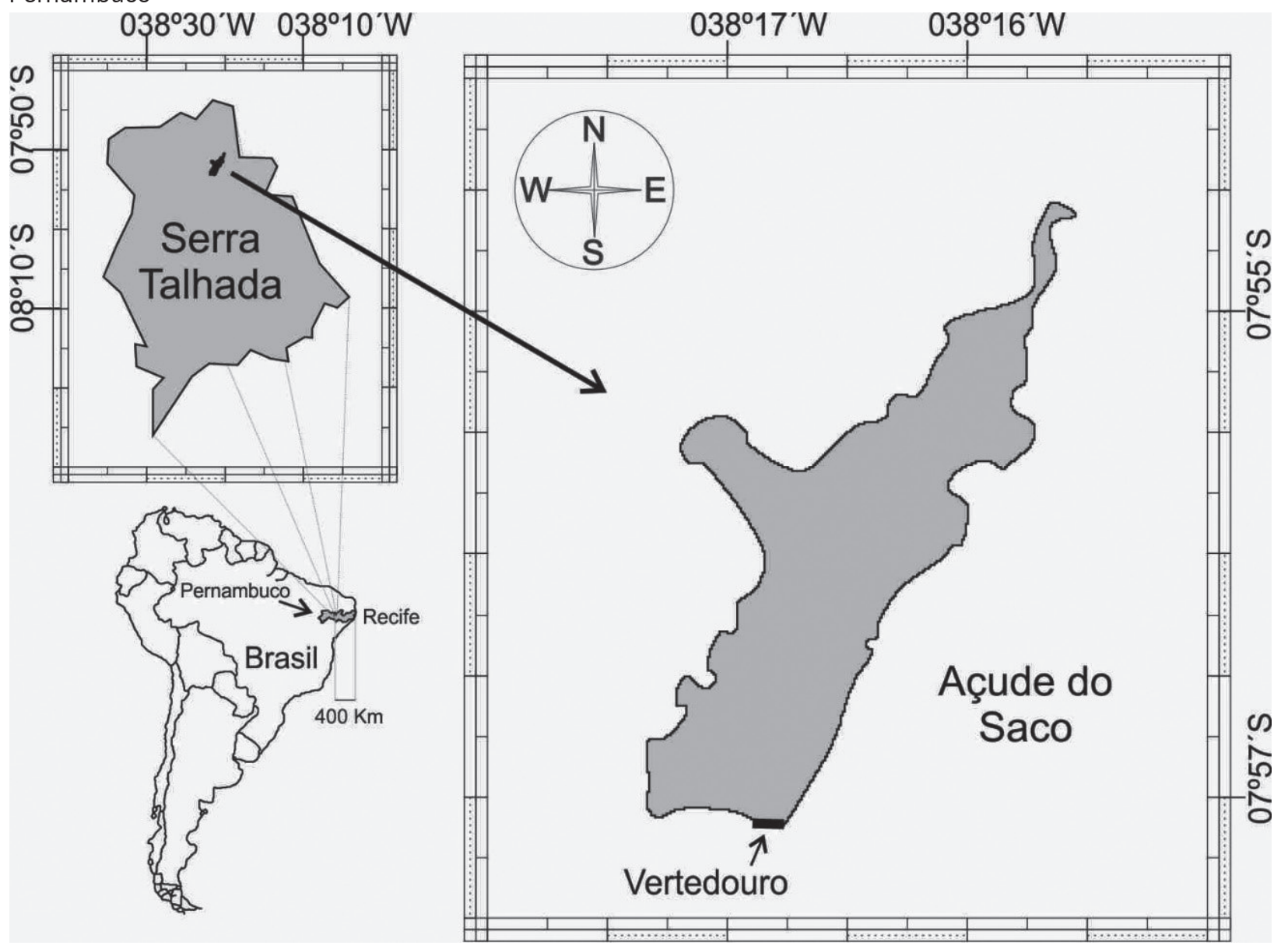

Fonte: Elaborada pelos autores (2013) 


\section{Batimetria}

As coletas dos dados para batimetria foram realizadas nos dias 29 de setembro e 07 de dezembro do ano de 2010, período seco, e 18 de março e 10 de junho do ano 2011, período chuvoso. Essas datas foram escolhidas visando observar os possíveis contrastes ocorridos devido à variação do período seco e chuvoso, que é bem acentuada nessa região.

Os dados foram coletados a bordo de um barco a motor empregado no deslocamento dentro do açude. A equipe de coleta foi composta por quatro pesquisadores, cujas funções foram divididas em condução da embarcação, observação da posição e profundidade, anotação dos valores observados e observação visual de perigos à navegação.

As coordenadas geográficas (eixos $x$ e y) foram obtidas com auxílio de um localizador via satélite GPS e as profundidades (eixo z) foram determinadas utilizando um ecobatímetro. A distância determinada entre os pontos amostrados foi de aproximadamente 50 metros. Os dados foram interpolados obtendo como resultado modelos digitais do terreno (MDT), utilizando software Surfer ${ }^{\circledR}$ 8.0. Como método de interpolação foi utilizada a "Krigagem" de uso comum no software.

Com base nos modelos, foram determinados os limites geográficos e analisada a variação sazonal da capacidade aquícola, além de estimadas as profundidades desde a margem até a porção central.

Foi utilizada uma régua liminétrica colocada no vertedouro para analisar a variação vertical da lâmina-d'água e, desta forma, identificar se a variação do volume total de água está relacionada com assoreamento ou ocorrência de elevada taxa de evapotranspiração.

\section{Variação sazonal do volume do Açude do Saco}

Os quatro levantamentos realizados deram origem aos MDTs ilustrados de três maneiras, mapas de pontos, mapas de relevo e os mapas em 3D, objetivando conhecer o comportamento do açude durante esse período.

Utilizando-se do mesmo programa computacional, estimou-se o volume total do açude para cada um dos quatro períodos analisados. Para tal, foram utilizadas as coordenadas geográficas e profundidades em cada ponto, obtendo como resultado um valor aproximado do volume real de água presente no açude em cada período.

\section{Capacidade do Açude do Saco}

Para estimativa da capacidade máxima do açude por período, foi adicionado a cada uma das profundidades coletadas o valor referente à distância da lâmina-d'água até o vertedouro. Em seguida, geraram-se novos MDTs com os valores obtidos para cada período e calculou-se o volume máximo estimado do açude para cada levantamento realizado.

\section{Assoreamento do Açude do Saco}

Com base nos valores do volume total estimado, foi feita a análise de assoreamento para os quatro períodos analisados. Uma vez que esse valor considera o açude em sua capacidade máxima, a variação está diretamente relacionada à possível ocorrência de assoreamento. Foram, então, consideradas as seguintes possibilidades:

- O volume aumenta: está ocorrendo um desassoreamento;

- O volume se mantém: não está ocorrendo assoreamento;

- O volume diminui: o açude está sendo assoreado. 


\section{Resultados e discussão}

\section{Variação sazonal do volume}

A partir dos dados coletados, foi gerado um mapa de contornos (Figura 2) para cada levantamento, no qual são observadas as linhas de mesma profundidade presentes no açude. As maiores profundidades foram observadas na área central e próxima ao vertedouro do açude no primeiro levantamento, sendo a maior delas observada próximo ao vertedouro, alcançando 10,9 m. As áreas mais rasas se localizaram às margens do açude, até atingir 0 (zero) m. Nota-se que no quarto levantamento as profundidades aumentaram em relação aos três anteriores, em decorrência das chuvas e consequente aumento de volume do açude nesse período.

Figura 2. Mapa de contornos das batimetrias realizadas em 29 set. 2010 (A), 07 dez. 2010 (B), 18 mar. 2011 (C) e 10 jun. 2011 (D) no Açude do Saco, Serra Talhada (PE) (profundidade em metros)

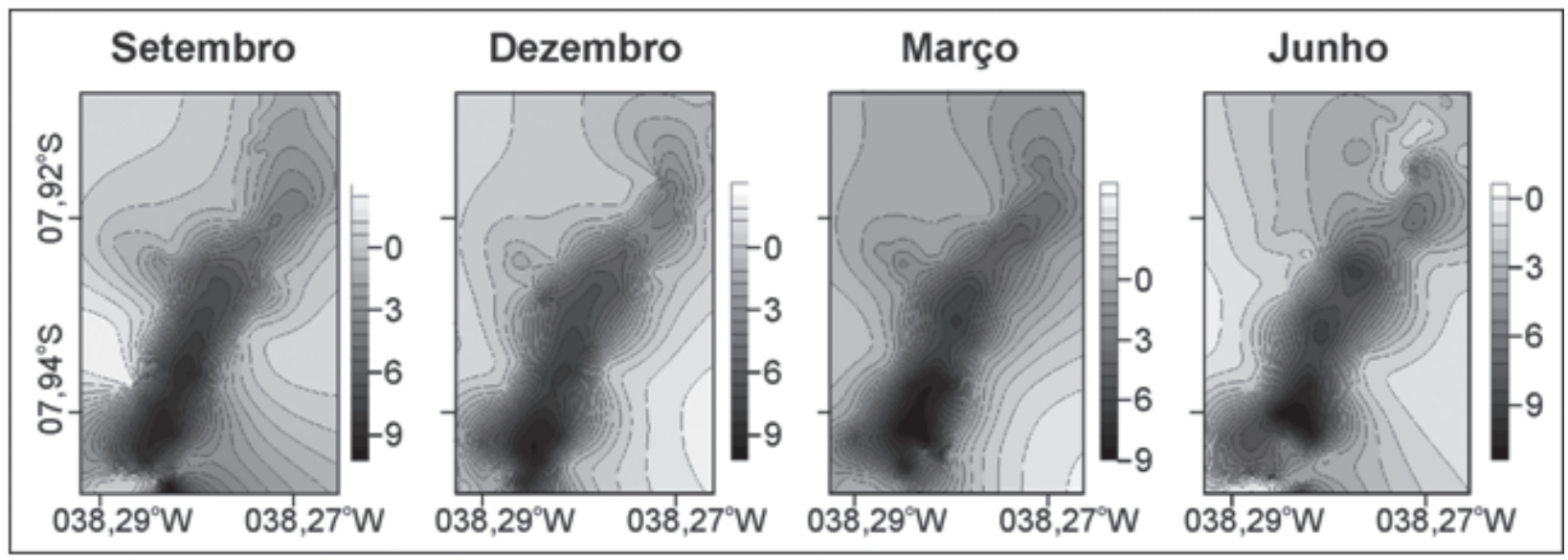

Fonte: Elaborada pelos autores (2013)

Com base nos levantamentos batimétricos realizados, observou-se que o Açude do Saco, por ser um açude de dimensões reduzidas, não apresenta grandes profundidades ao longo de seu curso, sendo a maior delas de 10,9 m, realizada no mês de setembro. Esse fato comprova a teoria de Hayes (1957), que trabalhou com as dimensões de 500 lagos de todo o mundo, demonstrando que, em geral, quanto maior a área do lago, maior será sua profundidade.

O perfil batimétrico do açude é demonstrado na Figura 3 com uma representação em terceira dimensão a partir dos pontos coletados, na qual é possível observar a conformação do açude no período analisado, bem como a distribuição das profundidades ao longo do açude representadas por cores. Nota-se que no terceiro levantamento é perceptível a diminuição do volume de água do açude, quando comparado aos anteriores, enquanto que no quarto levantamento houve aumento. 
Figura 3. Mapa em terceira dimensão das batimetrias realizadas em 29 set. 2010 (A), 07 dez. 2010 (B), 18 mar. 2011 (C) e 10 jun. 2011 (D) no Açude do Saco, Serra Talhada (PE)

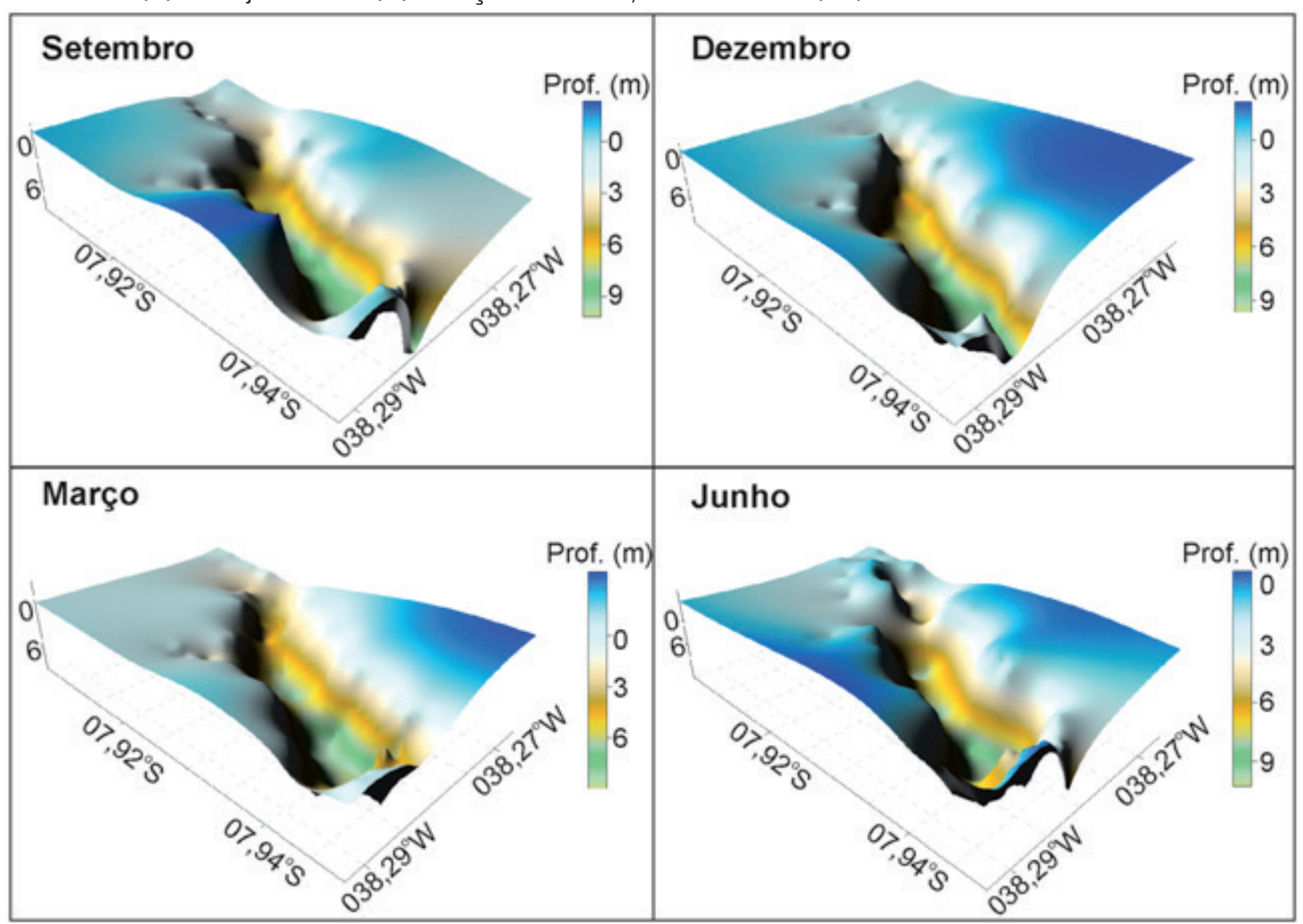

Fonte: Elaborada pelos autores (2013)

Com base nos mapas gerados ao longo dos quatro períodos analisados, foi possível notar uma compartimentação bem definida do açude, com áreas profundas no seu centro e nas proximidades do vertedouro e áreas mais rasas nas regiões próximas às margens, mesmo nos períodos com menor volume de água, fato semelhante ao comprovado por Resk, Bezerra Neto e Coelho (2007) em seu trabalho realizado na Lagoa da Pampulha, Belo Horizonte (MG). Essa compartimentação, também encontrada na Lagoa da Pampulha, embora menos acentuada, pode impor condições ecológicas e limnológicas especiais ao sistema, o que por sua vez influenciaria a estrutura ecológica ali existente, tais como plâncton, macrófitas aquáticas e até mesmo a própria comunidade de peixes.

A partir dos perfis batimétricos obtidos neste trabalho, observou-se que o açude está localizado em um terreno bastante acidentado, ideal para a acumulação de água. A presença de tanques-rede, redes e armadilhas de pesca em seu curso é um fato que comprova sua capacidade no que se refere à pesca e aquicultura, as quais já vêm sendo desenvolvidas pelas comunidades que vivem em seu entorno.

Ao realizar o cálculo de volume de água aproximado, obteve-se o valor de $26.056 .472 \mathrm{~m}^{3}$ de água em setembro de 2010; verificou-se uma diminuição no mês de dezembro do mesmo ano (23.570.234 $\mathrm{m}^{3}$ ), sendo esse o período seco. 0 volume de água continuou diminuindo em março de 2011 (19.738.857 $\mathrm{m}^{3}$ ), no entanto, aumentou bastante no mês de junho, atingindo 35.319.065 $\mathrm{m}^{3}$, com os dois últimos correspondendo ao período chuvoso. Esse volume é bem próximo ao valor 36.000.000 $\mathrm{m}^{3}$, citado por Almeida e Lima (2009), como sendo a capacidade máxima do açude. 
Segundo Almeida e Lima (2009) e Andrade et al. (2009), o Açude do Saco possui cerca de $36.000 .000 \mathrm{~m}^{3}$ de água. Atribuindo esse valor como referência, pode-se afirmar que no primeiro momento o açude apresentava $72,4 \%$ desse total, no segundo momento o volume de água foi de $62,5 \%$, no terceiro encontrou-se o menor percentual (54,8 \%) e para o último momento obteve-se o maior valor de todos e o qual se aproxima muito do valor que consta em bibliografia, chegando a 98,1 $\%$ desse total. Isso mostra que, mesmo no momento em que o açude apresentou o menor volume de água, o açude ainda contava com mais da metade da capacidade anteriormente citada.

\section{Capacidade}

Para determinação da capacidade máxima do açude, foi somado, para cada uma das profundidades obtidas, o valor da distância da lâmina-d'água até o vertedouro. No primeiro período analisado, essa distância foi de 1,84 m; no segundo, de 2,5 m; no terceiro, de 2,55 m; no quarto levantamento, $1,07 \mathrm{~m}$.

Com isso, gerou-se um mapa de contorno com profundidades estimadas (Figura 4), as quais representam os limites máximos do açude nesses períodos. A profundidade máxima do açude foi observada durante o primeiro levantamento, atingindo $12,8 \mathrm{~m}$.

Figura 4. Mapa de contornos e mapa em três dimensões do volume máximo estimado, referente às batimetrias realizadas em 29 set. 2010 (A, B), 07 dez. 2010 (C, D), 18 mar. 2011 (E, F) e 10 jun. 2011 (G, H), no Açude do Saco, Serra Talhada (PE) (Profundidade em metros)

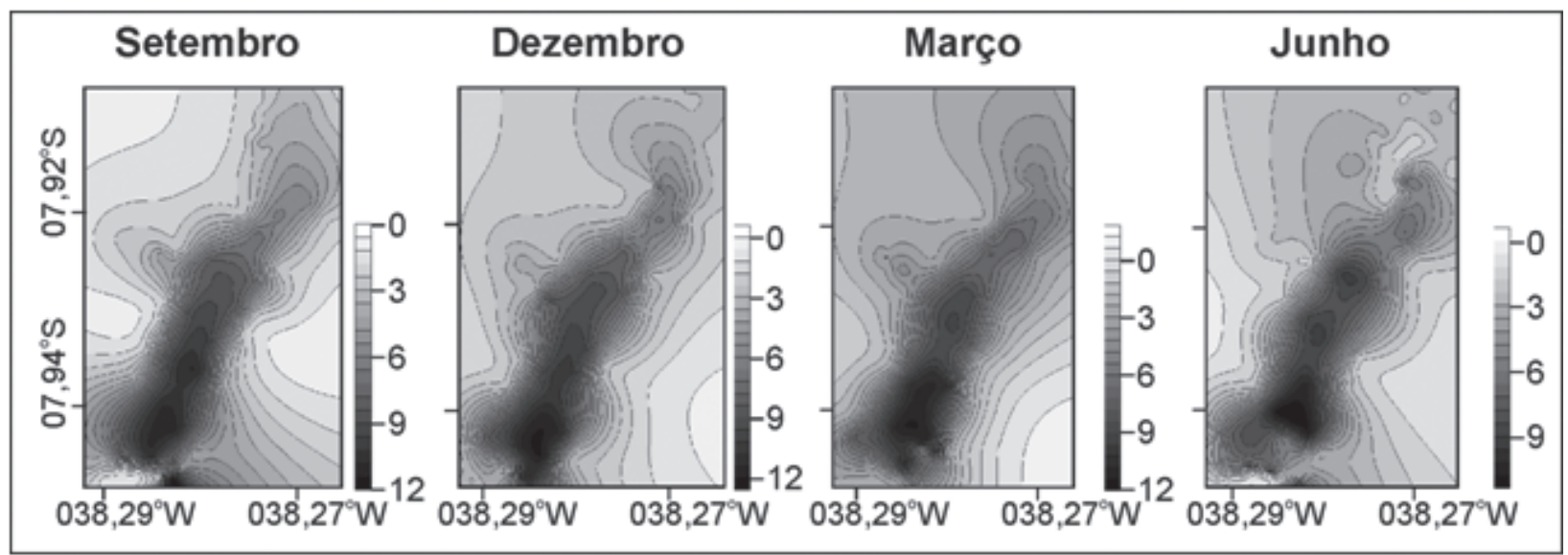

Fonte: Elaborada pelos autores (2013)

Na figura 5, observam-se os perfis batimétricos da conformação do açude em sua capacidade máxima em volume de água. 
Figura 5. Mapa em três dimensões do volume máximo estimado, referente às batimetrias realizadas em 29 set. 2010 (A, B), 07 dez. 2010 (C, D), 18 mar. 2011 (E, F) e 10 jun. 2011 (G, H) no Açude do Saco, Serra Talhada (PE)

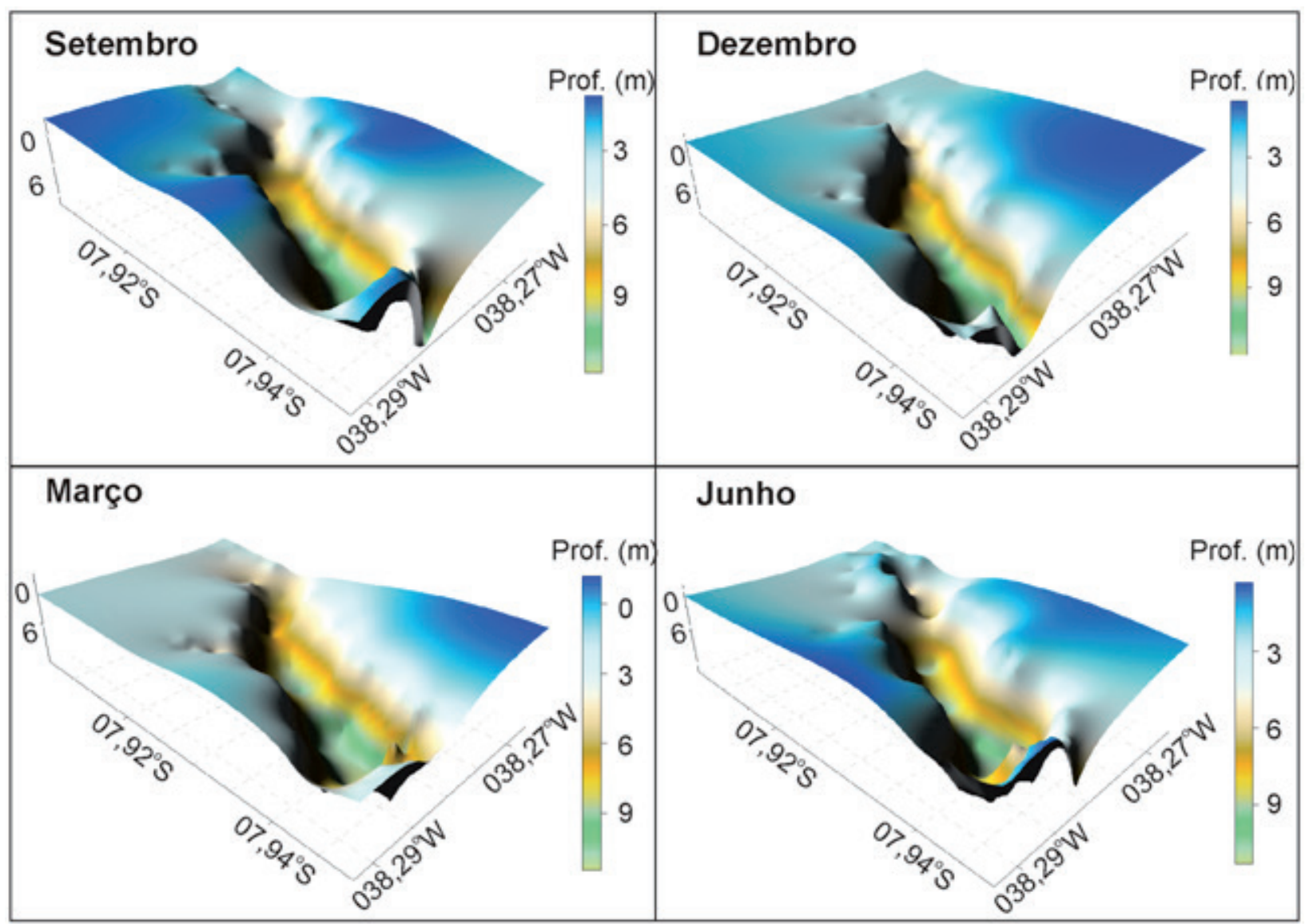

Fonte: Elaborada pelos autores (2013)

O volume máximo que o Açude do Saco pode atingir, limitado pela altura do vertedouro, seria de $49.566 .189 \mathrm{~m}^{3}$ no primeiro período, $49.100 .000 \mathrm{~m}^{3}$ no segundo, $48.460 .673 \mathrm{~m}^{3}$ no terceiro e $50.800 .941 \mathrm{~m}^{3}$ no quarto levantamento.

\section{Assoreamento}

Com base na oscilação da curva de volume total estimado (Figura 6), pode-se afirmar que não ocorreram variações significativas na capacidade total do açude que possam indicar um processo de assoreamento nesse período. Dessa maneira, as perdas de volume que ocorreram entre os períodos e são visíveis pelos valores apresentados estão relacionadas às perdas por evaporação e infiltração e os ganhos com o aumento do volume de chuvas, principalmente no ultimo período analisado. Assim, conclui-se que tais variações não representam níveis de assoreamento no Açude do Saco. 
Figura 6. Variação do volume (real e estimado) do Açude do Saco, Serra Talhada (PE)

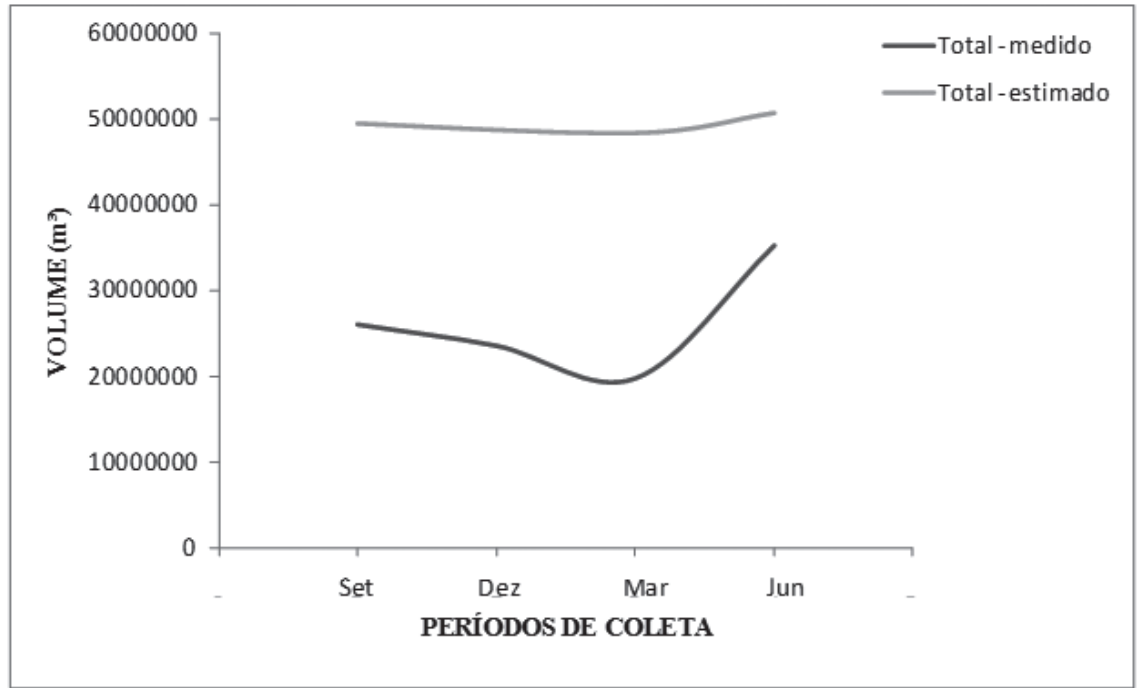

Fonte: Elaborada pelos autores (2013)

De acordo com Lima (2009), vários trabalhos são desenvolvidos com o objetivo de determinar taxas de assoreamento em reservatórios, utilizando, para isso, levantamentos batimétricos. Contudo, os trabalhos citados por ele apresentam taxas significativas de assoreamento, diferentemente do encontrado no Açude do Saco. Uma possível explicação para essa diferença pode ser o tipo de solo presente no local onde se encontra o açude, por ser seco e de textura mais dura, ocasionando menor quantidade de sedimento carreado para o seu interior. Outro fator importante, usado como uma possível justificativa, é o clima do local, quente e com ventos de velocidade reduzida, o que também reduz a quantidade de sedimento externo, que pela ação dos ventos, vai para o interior do açude.

$\mathrm{O}$ volume de chuvas que incidiu sobre a área e, consequentemente, sobre o açude variou muito durante o período estudado (Figura 7). A partir do gráfico, é possível perceber que há um intervalo de tempo entre o período em que se iniciam as chuvas e o momento em que o açude aumenta seu volume.

Figura 7. Relação entre o volume real de água em cada levantamento e a quantidade de chuvas mensal (dados pluviométricos do ITEP)

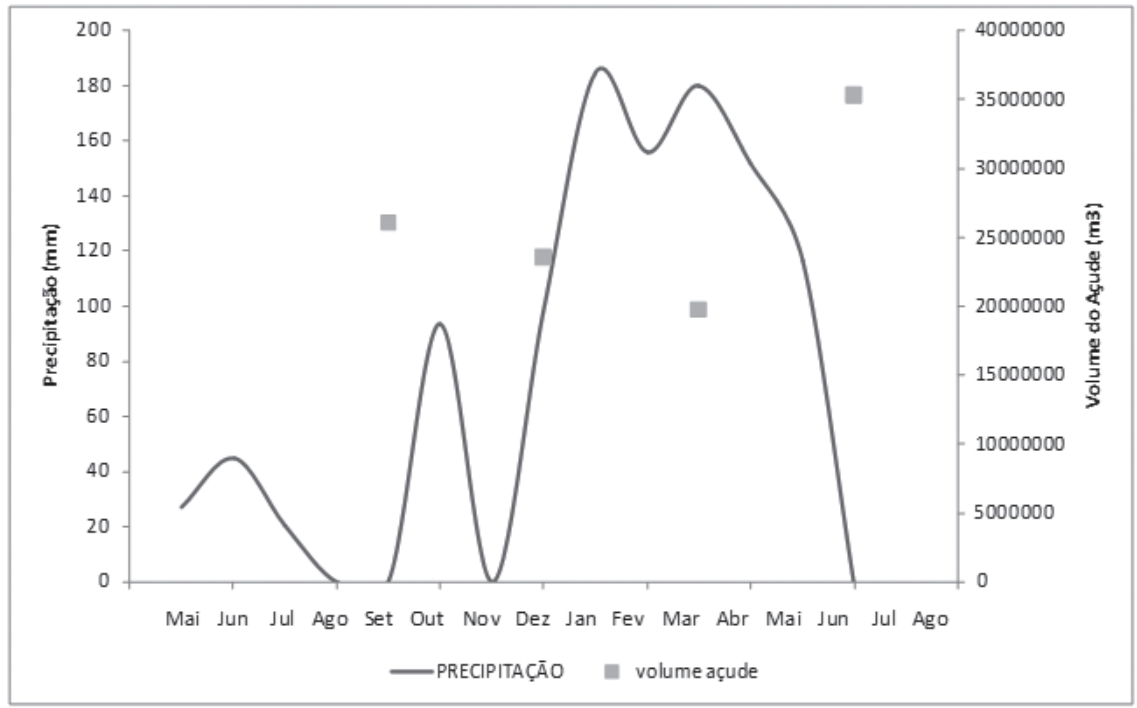

Fonte: Elaborada pelos autores (2013) 
Pela relação entre o volume do açude e a precipitação média durante o período avaliado não foi possível evidenciar uma resposta imediata ao aumento de volume de chuvas, ou seja, quando ocorreu o aumento na precipitação, o açude ainda demorou um pouco para aumentar seu volume, sendo necessário um período de aproximadamente 6 meses com chuvas constantes. Tal fato pode ser explicado pela dimensão do açude, uma vez que em açudes menores na própria região essa resposta é bem mais rápida. Araújo et al. (2010), ao trabalharem com o Açude Nossa Senhora de Fátima na cidade de Pesqueira (PE), relataram um aumento rápido do volume, pois em cerca de dois meses de chuvas acentuadas, esse açude já atingia seu máximo volume de $44.367 .000 \mathrm{~m}^{3}$ de água, bem inferior ao do Açude do Saco. Essa característica também foi observada para o Açude da Cachoeira, localizado na cidade de Serra Talhada, um açude menor que o Açude do Saco (SILVA et al., 2007). Nele, em um período de seis meses de análise, observou-se um aumento de volume de aproximadamente 7.000.000 $\mathrm{m}^{3}$ de água. A explicação cabível para essa resposta mais lenta é o fato de a evapotranspiração ser superior ao volume de água de origem pluvial. Somente após um determinado período de chuvas constantes, em que o solo circunvizinho é encharcado, é que o volume recebido é superior ao volume perdido.

\title{
Conclusões
}

0 açude apresentou elevada variação no volume total, saindo de um volume mínimo de 19.738.857 $\mathrm{m}^{3}$ em março de 2011 até atingir o volume máximo observado de $35.319 .065 \mathrm{~m}^{3}$. Apesar disso, é possível concluir que tais variações não causam danos às atividades desenvolvidas no local, como pesca e aquicultura, uma vez que mesmo o menor volume encontrado ainda é suficiente para manutenção dessas atividades.

\section{Seasonal variation of bathymetric profile of Açude do Saco, Serra Talhada, Pernambuco, Brazil}

\begin{abstract}
Bathymetry is an important process that allows the study of the characteristics of water bodies and their variations throughout the year. Samplings were carried out quarterly (September and December 2010, March and June 2011) alongside bathymetric data survey. The collected data were interpolated using Surfer ${ }^{\circledR}$ 8.0, which also allowed the making of DTM (digital terrain model) and calculations for the actual and maximum estimated volume. It was observed that the weir has wide range of depths. The volume varied widely, from $19,738,857 \mathrm{~m}^{3}$ in the third survey to $35,319,065$ $\mathrm{m}^{3}$ in the fourth one, when it reached the highest volume observed. No significant siltation occurred in this period. The variation found indicates that the main source of water is the rain. Despite the varied volume found, the weir presented conditions for the development of activities such as fishing and aquaculture.
\end{abstract}

Keywords: Water bodies. Weir. DTM. 


\section{Referências}

ALMEIDA, P. R. S.; LIMA, J. R. C. Influências da criação e beneficiamento de Peixes no IPA para a população da Fazenda Saco - Serra Talhada (PE). In: IX JORNADA DE ENSINO PESQUISA E EXTENSÃO (JEPEX). 2009, Serra Talhada (PE). Anais... Serra Talhada [9], 2009, p. 01-03.

ANDRADE, L. P.; CORREIA NETO, J. S.; LUSTOSA, G. L. C.; ARAÚJO, N. M.; CAMELlO NeTO, A. A. A. Gestão Sustentável da Piscicultura Artesanal no Açude da Fazenda Saco em Serra Talhada/PE. In: SOCIEDADE BRASILEIRA DE ECONOMIA, ADMINISTRAÇÃO E SOCIOLOGIA RURAL. 2009, Porto Alegre (RS). Anais... Porto Alegre [s.n.], 2009, p. 01-04.

ARAÚJO, P. R. M.; MONTENEGRO, A. A. A.; SILVA, J. R. L.; ARAÚJO, V. T. Avaliação da Precipitação e Enchimento do Açude Nossa Senhora de Fátima localizado na bacia do Riacho Jatobá - PE. In: X JORNADA DE ENSINO, PESQUISA E EXTENSÃO (JEPEX)- UFRPE. 2010, Recife - PE. Anais... Recife [10], 2010, p. 01-03.

BICUDO, C. E. M.; TUNDISI, J. G.; SCHEUENSTUHL, M. C. B. Águas do Brasil: análises estratégicas. São Paulo, Instituto de Botânica, 2010.

CAMPECHE, D. F. B.; PEREIRA, L. A.; FIGUEIREDO, R.; BARBALHO, M.; PAULINO, R. V.; SANTOS, N. G. N. Caracterização Limnológica e Morfometria de açudes dependentes de chuva povoados com Tambaqui (Colossoma macropomum) no Semi-árido nordestino. In: $1^{\circ}$ CONGRESSO BRASILEIRO DE PRODUÇÃO DE PEIXES NATIVOS DE ÁGUA DOCE, $1^{\circ}$ CONGRESSO DE PISCICULTORES DE MATO GROSSO DO SUL. 2009, Petrolina - PE. Anais... Petrolina, 2009, p. 01-06.

DINIZ, C. L.; BARBOSA, J. E. L.; OVRUSKI, B. S. Variabilidade temporal (Nictemeral e Sazonal) das condições limnológicas de açudes do trópico semi-árido Pernambucano. Revista de Biologia e Ciências da Terra, n. 2, p. 1-19, jul./dez. 2006. Disponível em: <http://joaootavio.com.br/bioterra/ workspace/uploads/artigos/acude-51818c2384fbf.pdf>. Acesso em: 15 nov. 2012.

ESTEVES, F. A.; Fundamentos de Limnologia. 2. ed. Rio de Janeiro: Interciência, 1998.

FANTIN-CRUZ, I.; LOVERDE-OLIVEIRA, S.; GIRARD, P. Caracterização morfométrica e suas implicações na limnologia de lagoas do Pantanal Norte. Acta Scientiarum. Biological Sciences, v. 30, n. 2, p. 133-140, 2008. Disponível em: <http://www.redalyc.org/pdf/1871/187116050003.pdf>. Acesso em: 12 mar. 2013.

GUIMARÃES, C. L.; RIBEIRO, C. N.; VIEIRA, L. J. S. Levantamento batimétrico do Açude Paraíso São Francisco (PB). Revista Verde, v. 1, n. 2, p. 1-07, 2009.

GUimarÃES, C. E. P.; CARNeIRO, L. B.; HeRMógeneS, L. S.; PINHEIRO, D. M.; MiRANDA, E. C.; FÉLIX, M. C. Avaliação da Qualidade de Água de Viveiros Utilizados para Cultivo de Tambaqui no CERAQUA/CODEVASF. In: 33a REUNIÃO ANUAL DA SOCIEDADE BRASILEIRA DE QUÍMICA. 2008, Maceió-AL, Anais... Maceió [33], 2008. p. 01.

HAYES, F. R. On the variation in bottom fauna and fish yield in relation to the trophic level and lake dimensions. Journal of the Fisheries Research Board of Canada, v. 14, n. 28, p. 1-32, 1957. 
LIMA, V. T. A.; CAMPECHE; D. F. B.; PEREIRA, L. A. Caracterização da água de açudes com peixes no Semiárido Pernambucano. Revista Ciências Agrárias e Ambientais, v. 7, n. 4, p. 395-405, 2009.

LIMA, Y. C. P. Análise do Assoreamento de um pequeno reservatório: Estudo de caso Açude Boqueirão, Aiuaba, Ceará. 2009. 85 f. Tese (Doutorado). Universidade Federal do Ceará - UFC, Fortaleza, 2009.

PAREDES, L. A. L. Estudio Limnológico del Lago de Guija, Determinación de su estado de eutrofización. 2008. 67 f. Dissertação (Mestrado). Universidad de San Carlos de Guatemala, Facultad de Ingeniería, Escuela de Estudios de Post-Grado, Ciudad de Guatemala, 2008. Disponível em: <file:///C:/Users/Usu\%C3\%A1 rio/Downloads/10226-16466-1-SM.pdf>. Acesso em: 02 fev. 2013.

PÉREZ-ROJAS, A.; BERMEO, R. T. O. Geomorfología y Batimetría del Lago de Catemaco, Veracruz, México. Revista anales del instituto de Ciencias deL mar y liminologia - UNAM, v. 19, n. 1, p. 1924. 1992.

RESK, R. P.; BEZERRA-NETO, J. F.; COELHO, R. M. P. Nova batimetria e avaliação de parâmetros morfométricos da Lagoa da Pampulha (Belo Horizonte, Brasil). Revista Geografias, v. 3, n. 2, p. 17-24, 2007. Disponível em: <file:///C:/Users/Usu\%C3\%A1 rio/Downloads/445-1350-1-PB.pdf>. Acesso em: 07 out. 2012.

SILVA, S. A. Avaliação do Assoreamento do Lago Bonsucesso, Jataí - G0. 96 f. Dissertação (Mestrado). Universidade Federal do Paraná - UFPR, Curitiba, 2007. Disponível em: <file:///C:/Users/ Usu\%C3\%A1rio/Downloads/16670-94234-1-PB.pdf> . Acesso em: 22 fev. 2012.

SILVA, H. P.; SILVA, M. D. R.; SOUZA, E. R.; RISSO, A. Utilização de imagens CBERS na avaliação do volume de água armazenada no Açude Cachoeira, no município de Serra Talhada, Pernambuco, Brasil. In: XIII SIMPÓSIO BRASILEIRO DE SENSORIAMENTO REMOTO. 2007. Florianópolis - SC, Anais... Florianópolis [13], 2007. p. 1167-1173.

SODRÉ, S. S. V. Hidroquímica dos Lagos Bolonha e Água Preta. Mananciais de Belém - PA. 114 f. Tese (Doutorado). Universidade Federal do Pará - UFPA, Belém, 2007. Disponível em: <http://repositorio.ufpa.br/jspui/bitstream/2011/2946/1/Dissertacao_HidroquimicaLagosBolonha.pdf>. Acesso em: 12 ago. 2013.

SOUZA JÚNIOR, C. Caracterização dos Impactos Antrópicos na área da Bacia do Açude Cajueiro Ribeirópolis-SE. 69 p. Monografia (Graduação). Universidade Federal de Sergipe - UFS, Aracaju, 2009.

\section{Histórico editorial:}

Submetido em: 10/05/2016

Aceito em: 16/08/2016 
Como citar:

$\underline{A B N T}$

LIMA, J. R. C.; MENDES, R. A. S. Variação sazonal do perfil batimétrico do Açude do Saco, município de Serra Talhada, Pernambuco, Brasil. Revista Agrogeoambiental, Pouso Alegre, v. 9, n. 3, p. 81-92, jul./set. Doi: http://dx.doi.org/10.18406/2316-1817v9n32017992

$\underline{A P A}$

LIMA, J. R. C. \& MENDES, R. A. S. (2017). Variação sazonal do perfil batimétrico do Açude do Saco, município de Serra Talhada, Pernambuco, Brasil. Revista Agrogeoambiental, Pouso Alegre, 9 (3), 81-92. Doi: http://dx.doi.org/10.18406/2316-1817v9n32017992

ISO

LIMA, J. R. C. e MENDES, R. A. S. Variação sazonal do perfil batimétrico do Açude do Saco, município de Serra Talhada, Pernambuco, Brasil. Revista Agrogeoambiental, 2017, vol. 9, n. 3, pp. 81-92. Eissn 23161817. Doi: http://dx.doi.org/10.18406/2316-1817v9n32017992

VANCOUVER

Lima JRC, Mendes RAS. Variação sazonal do perfil batimétrico do Açude do Saco, município de Serra Talhada, Pernambuco, Brasil. Rev agrogeoambiental. 2017 jul/set; 9(3): 81-92.

Doi: http://dx.doi.org/10.18406/2316-1817v9n32017992 